\title{
Location of NLS-RAR $\alpha$ protein in NB4 cell and nude mice
}

\author{
HUI WANG ${ }^{1,2^{*}}$, RONG YANG $^{2 *}$, LIANG ZHONG ${ }^{2}$, XIN-YU ZHU ${ }^{2}$, \\ PENG-PENG MA ${ }^{2}$, XIAO-QUN YANG ${ }^{2}$, KAI-LING JIANG ${ }^{2}$ and BEI-ZHONG LIU ${ }^{1,2}$ \\ ${ }^{1}$ Central Laboratory of Yong-Chuan Hospital, Chongqing Medical University, Chongqing 402160; \\ ${ }^{2}$ Key Laboratory of Laboratory Medical Diagnostics, Ministry of Education, Department of Laboratory Medicine, \\ Chongqing Medical University, Chongqing 400016, P.R. China
}

Received June 25, 2015; Accepted October 27, 2016

DOI: $10.3892 / \mathrm{ol} .2017 .5706$

\begin{abstract}
In the majority of acute promyelocytic leukemia (APL) cases, translocons produce a promyelocytic leukemia protein-retinoic acid receptor $\alpha$ (PML-RAR $\alpha)$ fusion gene. Studies have reported that neutrophil elastase (NE) cleaves bcr-1-derived PML-RA $\alpha$ in early myeloid cells, leaving only the nuclear localization signal (NLS) of PML attached to RAR $\alpha$. NLS-RAR $\alpha$ promotes cell growth and inhibits differentiation in response to ATRA. However, the mechanisms by which NLS-RAR $\alpha$ affects cell biological characteristics are yet to be fully elucidated. The present study found that the location of RAR $\alpha$ was altered after it was cleaved by NE. Firstly, $\mathrm{NE}$ was overexpressed during the preparation of recombinant plasmid NB-4/pCMV6-NE-Myc to cleave PML-RAR $\alpha$. The total protein expression levels of myc and NE and expression levels of NLS-RAR $\alpha$ in nucleoprotein were detected by western blotting. Location of NLS-RAR $\alpha$ protein was detected by immunofluorescence and confocal laser scanning. Secondly, a nude mice model was constructed and NE protein, NLS-RAR $\alpha$ and RAR $\alpha$ protein assays, and the location of NLS-RAR $\alpha$ and RAR $\alpha$ proteins were assessed as described. The present results showed that, compared with the control groups, the location of NLS-RAR $\alpha$ protein was predominantly detected in the nucleus, whereas $\operatorname{RAR} \alpha$ was mainly distributed in the cytoplasm. These findings were consistent with those of the nude mice model, and these may be used as a foundation to explain the occurrence mechanism of APL.
\end{abstract}

Correspondence to: Dr Bei-Zhong Liu, Key Laboratory of Laboratory Medical Diagnostics, Ministry of Education, Department of Laboratory Medicine, Chongqing Medical University, 1 Yixueyuan Road, Yuzhong, Chongqing 400016, P.R. China

E-mail: liubeizhong@cqmu.edu.cn

*Contributed equally

Key words: nuclear localization signal-retinoic acid receptor $\alpha$, location, NB4 cells, nude mice, acute promyelocytic leukemia

\section{Introduction}

As a member of the nuclear steroid/thyroid hormone receptor superfamily, retinoic acid receptor-alpha (RAR $\alpha$ ) is encoded by the RAR $\alpha$ gene mapped on chromosome 17q21 in humans (1). RAR $\alpha$ gene near the breakpoint of acute promyelocytic leukemia (APL) is thought to have a key role in the pathogenesis of APL, as RAR $\alpha$ acts as a ligand-dependent transcription factor to modulate the expression of target genes after stimulated by ATRA (2-4). Some studies declared that after it is synthesized and has undergone appropriate modification and stimulation by ATRA, RAR $\alpha$ can be transported from the cytoplasm to the nucleus. Thus, it is located both in cytoplasm and nucleus in a physiological manner. Promyelocytic leukemia (PML), which is encoded by a PML gene mapped on chromosome $15 \mathrm{q} 22$ in humans, contains a nuclear localization signal (NLS), an $\alpha$-helical coiled-coil region and B-Boxes (5). In 1991, it was discovered that the consistent chromosomal translocation of APL, $t$ (15:17), fused the RAR $\alpha$ gene to the PML gene on chromosome 15 (6), yielding the fusion protein PML-RAR $\alpha$ (7), which represents the etiologic agent of APL. This translocation has become the definitive marker for the disease and is detected in $95 \%$ of patients with APL (8). The aberrant PML-RAR $\alpha$ fusion product has a vital role in APL (9). It produces PML-RARa protein to inhibit the transcription of myeloid differentiation-associated gene, resulting in the blocking of the differentiation of granulocytes at the promyelocytic stage, thus promyelocytes were abnormally accumulated in the bone marrow (10). At last it leads to the occurrence of APL.

PML-RAR $\alpha$ fusion protein does not always have a role as a whole; it has been demonstrated that PML-RAR $\alpha$ fusion protein may be cut into two variant proteins in early myeloid cells by neutrophil elastase (NE), which is an early myeloid-specific serine protease (11). This type of cleavage action separates NLS from the PML gene and attaches it to RAR $\alpha$, which then named NLS-RAR $\alpha(61 \mathrm{kDa})$. These data suggested that the disruption of RAR $\alpha$ protein may be the critical cause of APL. Previous experimental studies in our laboratoy have demonstrated that NLS-RAR $\alpha$ protein interacts with JTV1 protein, ubiquilin 1 protein and glutamate ammonia ligase by using a yeast two-hybrid system and co-immunoprecipitation techniques $(12,13)$. NLS-RAR $\alpha$ is able to promote cell proliferation and induce cell differentiation, which is inhibited by ATRA though the expression of c-myc (14). 
As a specific signal mediated protein, NLS is a specialized sequence presented on certain proteins. NLS, which can help NLS-containing cargo protein reach the nucleus through the nuclear pore, was identified by the corresponding nuclear transport protein (5).

In order to explore the influence of NLS on NLS-RAR $\alpha$ protein location, pCMV6-NE-Myc plasmid was electroporated into NB4 cells and the subcutaneous tumor model in nude mice was constructed. Cells were detected and analyzed by western blotting, immunofluorescence and confocal laser scanning. The results of the present study may provide the foundation for further research of the mechanism of occurrence of APL.

\section{Materials and methods}

Cell line and culture. Human K562 cells (Institute for Biological Sciences, Shanghai, China) were maintained in RIPA 1640 culture medium supplemented with $10 \%$ fetal bovine serum (FBS; both Gibco; Thermo Fisher Scientific, Inc. Waltham, MA, USA). Human NB4 cells were stored in our own laboratory and maintained in RIPA 1640 culture medium supplemented with $10 \%$ fetal bovine serum. Cells were grown at $37^{\circ} \mathrm{C}$ in an atmosphere containing $5 \% \mathrm{CO}_{2}$. All of cells were cultured in medium that was replaced every two days. A vector map is shown in Fig. 1.

Electroporation and select. pCMV6-NE-Myc and pCMV-KZ-Myc plasmids were recombined by our own laboratory. Prior to electroporation, NB4 cells were washed with RIPA 1640 culture medium, counted, resuspended in culture medium to a cell density of $1 \times 10^{6}$ cells $/ \mathrm{ml}$, and incubated in an ice bath for $5 \mathrm{~min}$. Cells and plasmids $(20 \mu \mathrm{g} / \mathrm{ml})$ were mixed in RIPA 1640 culture medium and transferred into an electroporation cuvette (Lonza Inc., Allendale, NJ, USA). The electroporation apparatus (Lonza Inc.) was set at $250 \mathrm{~V}$ for $10 \mathrm{msec}$ using a $0.4-\mathrm{mm}$ cuvette. Following incubation at $37^{\circ} \mathrm{C}$ for $30 \mathrm{~min}, 1 \mathrm{ml}$ fresh RIPA 1640 culture medium supplemented with $10 \%$ fetal bovine serum was added and the cells grew at $37^{\circ} \mathrm{C}$ in an atmosphere containing $5 \% \mathrm{CO}_{2}$. Cells were selected by G418 (300 ng/ml; Invitrogen; Thermo Fisher Scientific, Inc.), for $>5$ weeks. Western blotting was used to assess the myc expression. Cells which stably expressed myc protein were referred to as NE-NB4. In the negative control group, KZ-NB4 cells were processed in the same way.

Total protein, cytoplasmic and nuclear protein extraction. For total protein extraction, cells in each group were washed with ice-cold phosphate-buffered saline and lysed in RIPA 1640 solution containing a protease inhibitor cocktail. Cytoplasmic and nuclear protein extraction was subsequently performed. Cells in each group were washed with ice-cold phosphate-buffered saline and treated with a nuclear protein extraction kit (Beyotime Institute of Biotechnology, Haimen, China). Following concentration determination by the BCA method, proteins were stored at $-80^{\circ} \mathrm{C}$.

Western blot assay. A total of $100 \mu \mathrm{g}$ protein from each group was separated by $12 \%$ sodium dodecyl sulfate-polyacrylamide gel electrophoresis and transferred to polyvinylidene difluoride membranes. These membranes were blocked for $4 \mathrm{~h}$ at room temperature in 5\% skim milk then incubated with the following primary antibodies overnight at $4^{\circ} \mathrm{C}$ : Anti-myc monoclonal antibody (1:500; cat. no. 2276; Cell Signaling Technology, Inc., Danvers, MA, USA), rabbit polyclonal antibody against RAR $\alpha$ (1:500; cat. no. sc-366090) and rabbit polyclonal antibody against NE (1:500; cat. no. sc-9520; both Santa Cruz Biotechnology, Dallas, TX, USA). Following washing, the membranes were incubated with secondary goat anti-mouse antibody (cat. no. ZM-0491) or goat anti-rabbit antibodies (both 1:1,000; cat. no. ZA-0448; both Zhongshan Goldenbridge Biotechnology Co., Ltd., Beijing, China) for $1 \mathrm{~h}$ at $37^{\circ} \mathrm{C}$. Following washing three times (10 min each time) in TBST, immunoreactive complexes were visualized using an enhanced chemiluminescence system (Bio-Rad Laboratories, Inc., Hercules, CA, USA). $\beta$-actin or Histone $\mathrm{H} 3$ served as an internal positive control. Protein bands were visualized using the Quantity One Software version 4.5.2 (Bio-Rad Laboratories, Inc.).

Immunofluorescence and confocal laser scanning. Following washing with PBS, the cells in each group were smeared onto slides, fixed with $4 \%$ paraformaldehyde for $20 \mathrm{~min}$ at $4^{\circ} \mathrm{C}$ and permeabilized in $0.1 \%$ Triton at room temperature for $10 \mathrm{~min}$. Prior to the primary antibody reaction, the cells were incubated with $10 \%$ goat serum (Beyotime Institute of Biotechnology) for $30 \mathrm{~min}$ at room temperature. Subsequently, the slides were incubated with rabbit polyclonal primary antibody against RAR $\alpha$ (1:200; Santa Cruz Biotechnology, Inc.) at $4^{\circ} \mathrm{C}$ for $8 \mathrm{~h}$, followed by incubation with fluorescein isothiocyanate (FITC)-conjugated goat anti-rabbit IgG (1:200; Zhongshan Goldenbridge Biotechnology Co., Ltd.) at room temperature for $1 \mathrm{~h}$. Following counterstaining with 4'6'-diamino-2-phenylindole dihydrochloride (DAPI; $1 \mu \mathrm{g} / \mathrm{ml} ; 5 \mathrm{~min}$ ) or PI (propidium iodide; $1 \mu \mathrm{g} / \mathrm{ml}$; $2 \mathrm{~min}$ ), cells were visualized by microscopes.

Cells were counterstained with DAPI were visualized by luorescence microscope (x400; Nikon Corp., Tokyo, Japan), and the cells counterstained with PI were scanned using confocal laser scanning microscope (magnification, 400x; Leica Microsystems GmbH, Wetzlar, Germany).

Nude mice models. A total of nine male nude mice (7-8 weeks old; 18-20 g) were randomly divided into three groups and inoculated by subcutaneous injection into the right front armpits with NE-NB4, NB4 and K562 cells, respectively. Animals were housed in a temperature-controlled $\left(24-25^{\circ} \mathrm{C}\right.$ and $50 \%$ humidity) pathogen-free environment with a 12 -h light/dark cycle, and provided with food and water ad libitum. Tumors were stripped in the first 10 days, cut into pieces and dissociated into single cell suspensions by Trypsin $(0.25 \%$; $3 \mathrm{~min})$. These cells were respectively named as Tumor-NE-NB4, Tumor-NB4 and Tumor-K562, and were analyzed by western blot, immunofluorescence and confocal laser scanning analysis, as outlined. All animal experiments were performed according to national laws. This study was approved by the Ethics Committee of Chongqing Medical University (Yongchuan, China).

Statistical analysis. Data was presented as the mean \pm standard deviation. Statistical analysis was performed using SPSS 17.0 software (SPSS, Inc., Chicago, IL, USA). Independent sample t-test was employed for compare the means between two groups. $\mathrm{P}<0.05$ was considered to indicate a statistically significant difference. 

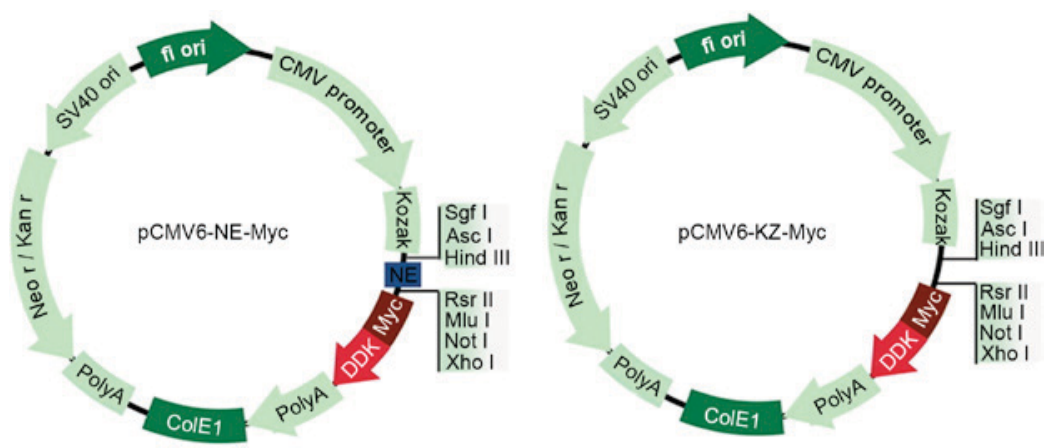

Figure 1. Vector map.

A
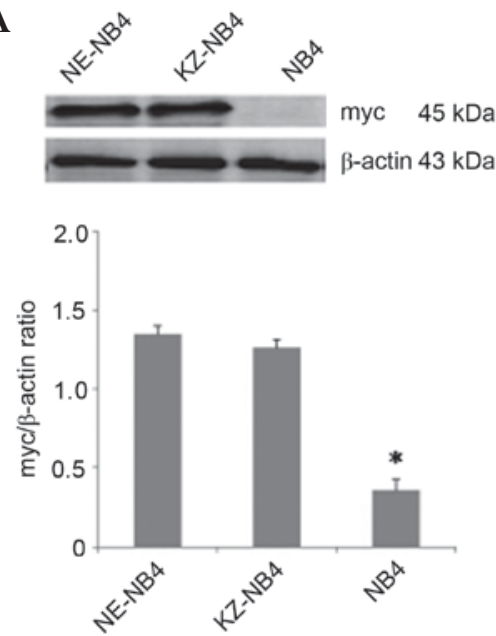

B
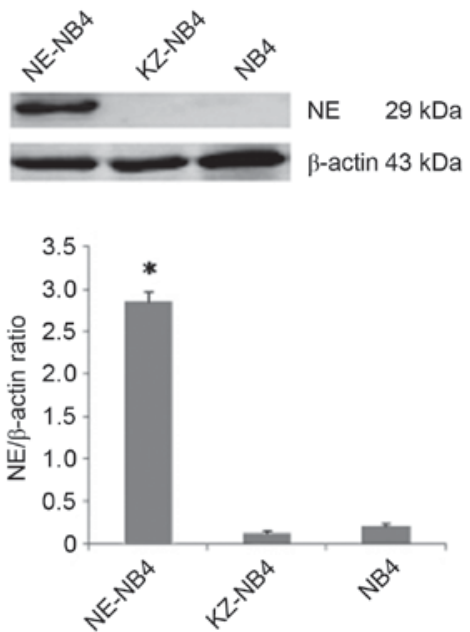

Figure 2. Expression of myc and NE in NE-NB4 cells. (A) Protein expression levels of myc were detected by western blot assay. When compared with the NB4 group, myc expression in the NE-NB4 and KZ-NB4 cells increased significantly $(\mathrm{P}<0.05)$. (B) Protein expression of NE was assessed by western blot assay. Protein expression levels of NE in the NE-NB4 cells were significantly increased, as compared with the controls $(\mathrm{P}<0.05)$. Data were expressed as the mean \pm standard deviation. ${ }^{*} \mathrm{P}<0.05$. NE, neutrophil elastase.

A
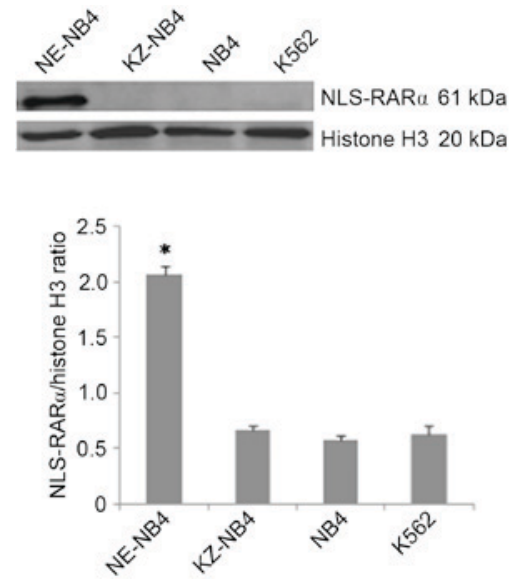

B
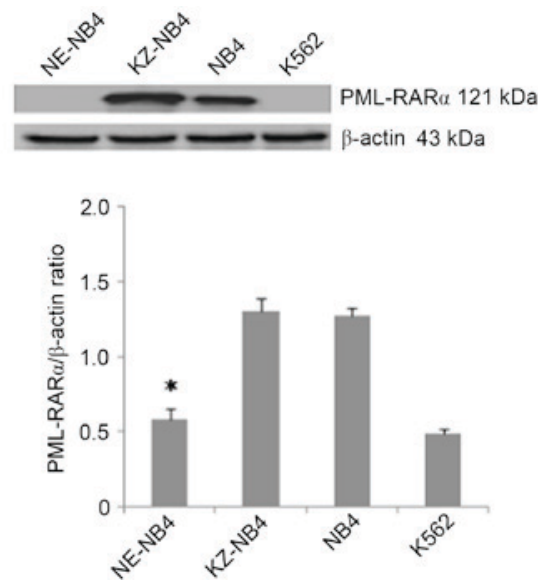

Figure 3. Expression of NLS-RAR $\alpha$ in nucleoprotein of NE-NB4 cells. (A) Protein expression levels of NLS-RAR $\alpha$ were detected in nucleoprotein of NE-NB4 cells by western blot assay. Protein expression levels of NLS-RAR $\alpha$ in the NE-NB4 cells were significantly increased, as compared with KZ-NB4, NB4 and K562 cells. (B) Expression of PML-RAR $\alpha$ in the cytoplasmic protein of NE-NB4 cells significantly decreased when compared with KZ-NB4 and NB4 cells $(\mathrm{P}<0.05)$. Data were expressed as the mean \pm standard deviation. " $\mathrm{P}<0.05$. NLS-RAR, nuclear localization signal-retinoic acid receptor; PML, promyelocytic leukemia protein; NE, neutrophil elastase.

\section{Results}

Expression of myc and NE in total protein of NE-NB4 cells. Western blot assay results demonstrated the presence of myc protein was confirmed in NE-NB4 and KZ-NB4 cells, compared with the NB4 group ( $\mathrm{P}<0.05$; Fig. 2A). Western blot assay also showed that NE protein was expressed in NE-NB4 cells $(\mathrm{P}<0.05$; Fig. 2B). 


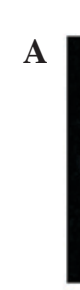

DAPI

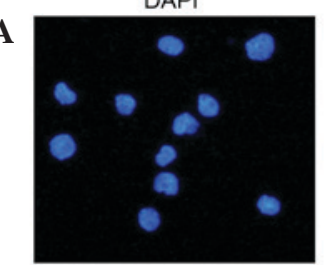

D

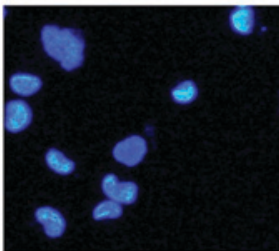

G

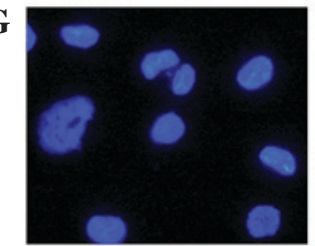

$\mathbf{J}$

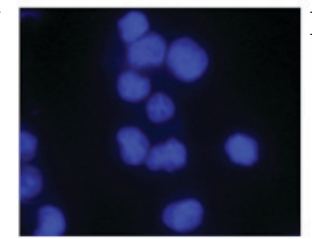

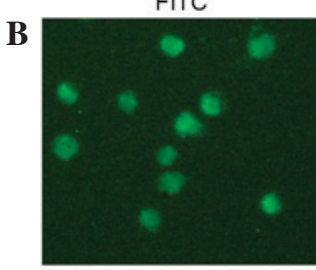
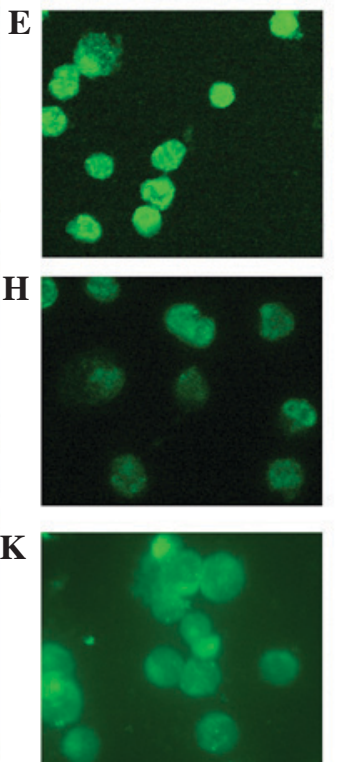
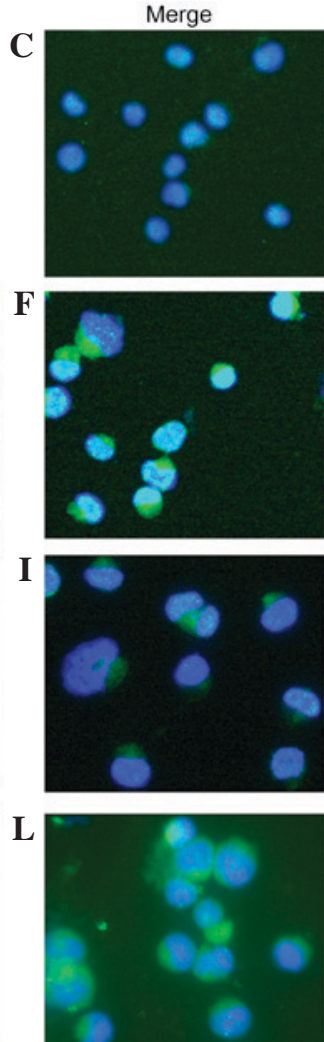

Figure 4. RAR $\alpha$ proteins in the (A-C) NE-NB4, (D-F) electrical KZ-NB4, (G-I) NB4 and (J-L) K562 groups were visualized by immunofluorescence staining with anti-RAR $\alpha$ antibody. Target protein was stained green by FITC; the nucleus was stained blue by DAPI. RAR, retinoic acid receptor; NE, neutrophil elastase; DAPI, 4'6'-diamino-2-phenylindole dihydrochloride; FITC, fluorescein isothiocyanate.
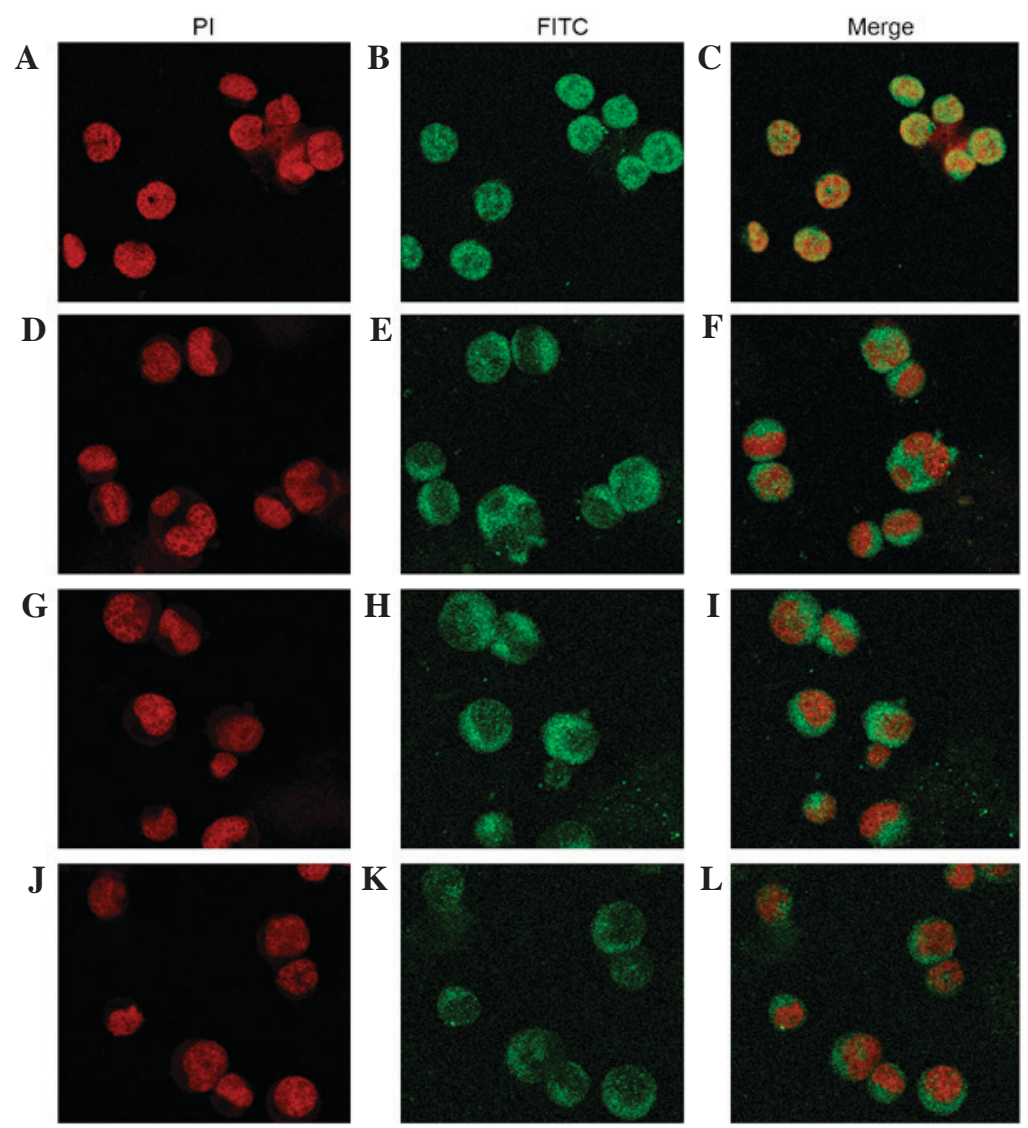

Figure 5. RAR $\alpha$ and NLS-RAR $\alpha$ proteins in the (A-C) NE-NB4, (D-F) electrical KZ-NB4, (G-I) NB4 and (J-L) K562 groups were visualized by confocal laser scanning staining with anti-RAR $\alpha$ antibody. Target protein was stained green by FITC; the nucleus was stained blue by PI. RAR, retinoic acid receptor; NE, neutrophil elastase; PI, propidium iodide; FITC, fluorescein isothiocyanate. 

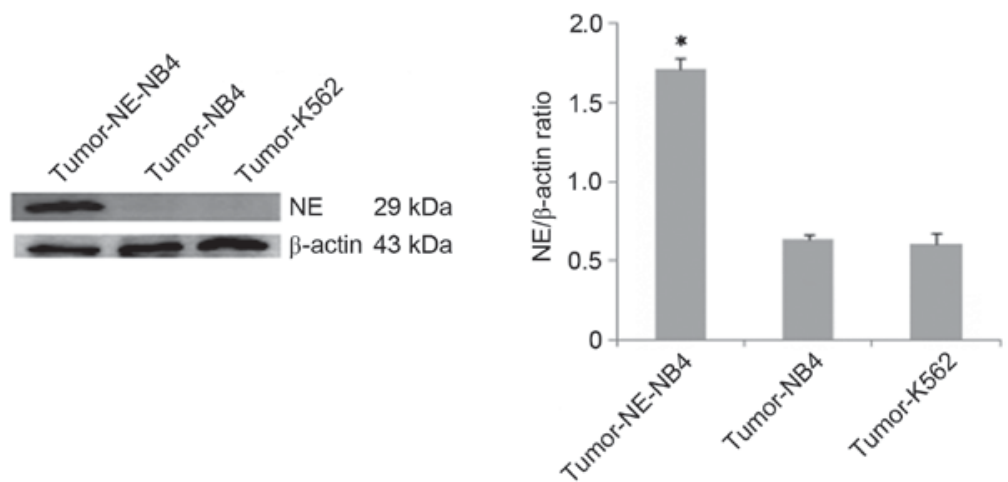

Figure 6. Protein expression of NE in Tumor-NE-NB4 cells, as assessed by western blot assay. Protein expression of NE in the Tumor-NE-NB4 cells was increased, as compared with the controls. Data were expressed as the mean \pm standard deviation. " $\mathrm{P}<0.05$ vs. Tumor-NB4 and Tumor-K562 cells. NE, neutrophil elastase.

A
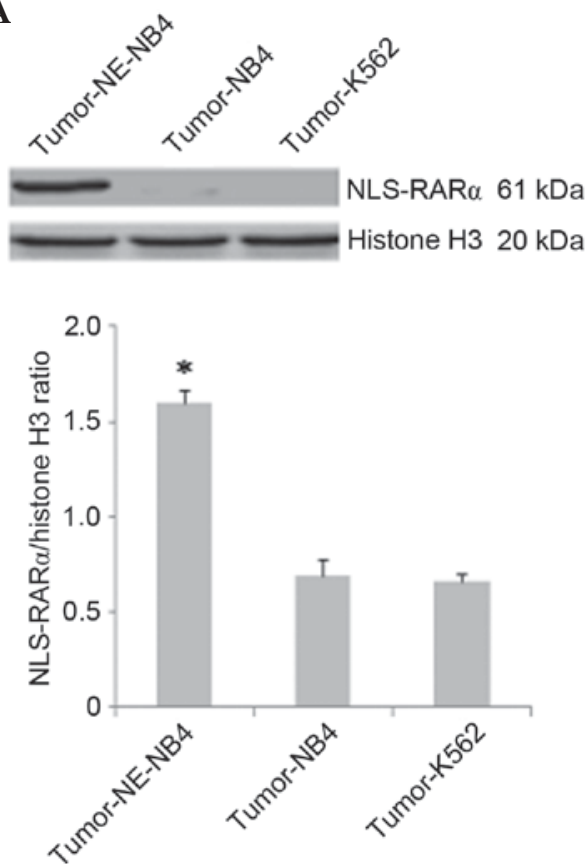

B
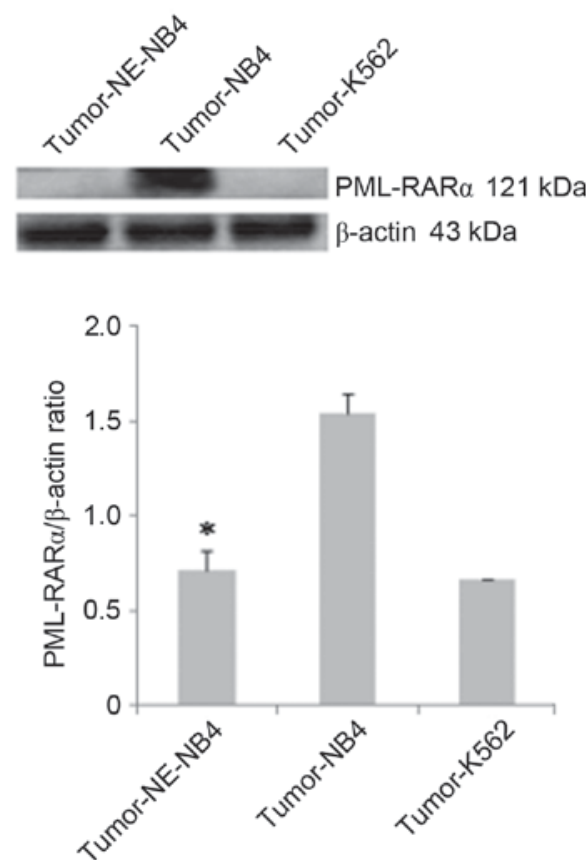

Figure 7. Expression of NLS-RAR $\alpha$ in nucleoprotein of Tumor-NE-NB4 cells. (A) NLS-RAR $\alpha$ protein was detected in the nucleoprotein of Tumor-NE-NB4 cells by western blot assay. Protein expression of NLS-RAR $\alpha$ in the Tumor-NE-NB4 cells was significantly increased, as compared with Tumor-NB4 and Tumor-K562 cells. (B) Expression of PML-RAR $\alpha$ in the cytoplasmic protein of Tumor-NE-NB4 cells was significantly decreased, as compared with Tumor-NB4 cells and Tumor-K562. Data were expressed as the mean \pm standard deviation. " $\mathrm{P}<0.05$ vs. Tumor-NB4 and Tumor-K562 cells. NLS-RAR, nuclear localization signal-retinoic acid receptor; PML, promyelocytic leukemia protein; NE, neutrophil elastase.

Expression of NLS-RAR $\alpha$ in nucleoprotein of NE-NB4 cells. Western blot assay results showed that nucleoprotein of NE-NB4 cells confirmed the presence of NLS-RAR $\alpha$ protein $(\mathrm{P}<0.05$; Fig. 3A). Western blot assay also indicated that PML-RAR $\alpha$ were expressed in the cytoplasmic protein of KZ-NB4 and NB4 cells $(\mathrm{P}<0.05$; Fig. 3B).

Immunofluorescence detection in NE-NB4 cells. The FITC area and nuclear DAPI staining areas almost overlapped in NE-NB4, suggesting that NLS-RAR $\alpha$ protein in the NE-NB4 group was predominantly presented in the nucleus (Fig. 4A-C). However, in the KZ-NB4 (Fig. 4D-F), NB4 (Fig. 4G-I) and K562 groups (Fig. 4J-L), the FITC-stained areas were markedly larger than the nuclear DAPI-stained areas. The nuclear areas were lightly stained, suggesting that other types of RAR $\alpha$ proteins in the
KZ-NB4, NB4 and K562 groups were presented in the cytoplasm and nucleus, and were predominantly distributed in the cytoplasm.

Confocal laser scanning of NE-NB4 cells. FITC-stained and nuclear PI-stained areas almost overlapped in NE-NB4, suggesting that NLS-RAR $\alpha$ protein in the NE-NB4 group was predominantly presented in the nucleus (Fig. 5A-C). However, in the KZ-NB4 (Fig. 5D-F), NB4 (Fig. 5G-I) and K562 (Fig. 5J-L) groups, the FITC-stained areas were markedly larger than nuclear PI-stained areas. The nuclear areas were lightly stained, suggesting that other types of RAR $\alpha$ proteins in KZ-NB4 group, NB4 group and K562 group were localized to the cytoplasm and nucleus, and were predominantly distributed in the cytoplasm. 

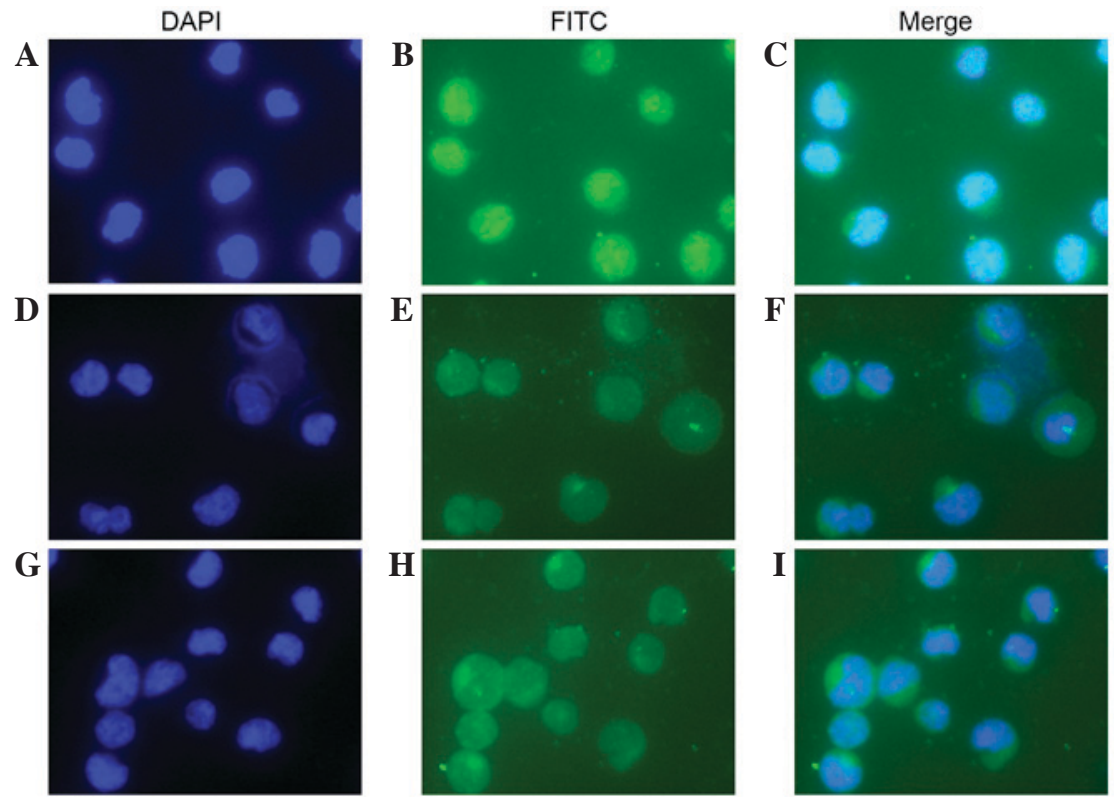

Figure 8. Immunofluorescence analysis. RAR $\alpha$ proteins in the (A-C) Tumor-NE-NB4, (D-F) electrical Tumor-NB4 and (G-I) Tumor-K562 groups were visualized by immunofluorescence staining with anti-RAR $\alpha$ antibody. Target protein was stained green by FITC; nucleus was stained blue by DAPI. RAR, retinoic acid receptor; NE, neutrophil elastase; DAPI, 4'6'-diamino-2-phenylindole dihydrochloride; FITC, fluorescein isothiocyanate.
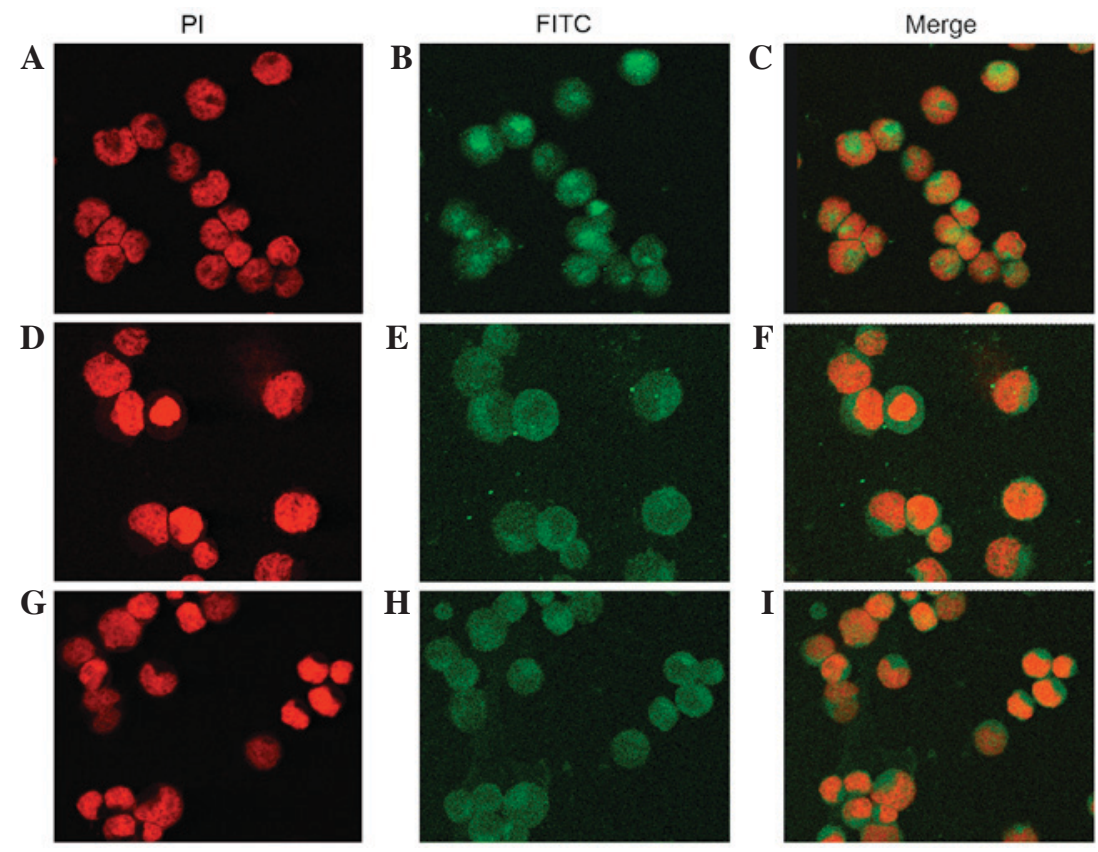

Figure 9. Immunofluorescence analysis. RAR $\alpha$ proteins in the (A-C) Tumor-NE-NB4, (D-F) electrical Tumor-NB4 and (G-I) Tumor-K562 groups were visualized by immunofluorescence staining with anti-RAR $\alpha$ antibody. Target protein was stained green by FITC; nucleus was stained blue by PI. RAR, retinoic acid receptor; NE, neutrophil elastase; PI, propidium iodide; FITC, fluorescein isothiocyanate.

Expression of NE in total protein of tumor-NE-NB4 cells. Western blot assay results indicated that the NE protein was expressed in the Tumor-NE-NB4 cells, while NE protein expression was low in Tumor-NB4 and Tumor-K562 cells (P<0.05; Fig. 6).

Expression of NLS-RAR $\alpha$ in nucleoprotein of Tumor-NE-NB4 cells. Western blot assay results demonstrated that the nucleoprotein of Tumor-NE-NB4 cells confirmed the presence of NLS-RAR $\alpha$ protein $(\mathrm{P}<0.05$; Fig. 7A). The results of western blot assay also showed that PML-RAR $\alpha$ was significantly expressed in the cytoplasmic protein of Tumor-NB4 cells, as compared with Tumor-NB4 and Tumor-K562 cells in the present study ( $\mathrm{P}<0.05$; Fig. 7B).

Immunofluorescence detection in tumor cells. The FITC-stained and nuclear DAPI-stained areas almost overlapped in Tumor-NE-NB4 cells, which suggested that NLS-RAR $\alpha$ protein in Tumor-NE-NB4 group was predominantly presented in the nucleus (Fig. 8A-C). However, in the electrical Tumor-NB4 
(Fig. 8D-F) and Tumor-K562 (Fig. 4G-I) groups, the FITC-stained areas were significantly larger than those of the nuclear DAPI-stained areas. These findings suggested that other types of RAR $\alpha$ proteins in the Tumor-NB4 and Tumor-K562 groups were presented in the cytoplasm and nucleus.

Confocal laser scanning tumor cells. The FITC-stained and nuclear PI-stained areas almost overlapped in Tumor-NE-NB4 cells, suggesting that NLS-RAR $\alpha$ protein in the Tumor-NE-NB4 group was predominantly presented in the nucleus (Fig. 9A-C). However, in the electrical Tumor-NB4 (Fig. 9D-F) and Tumor-K562 (Fig. 9G-I) groups, FITC-stained areas were significantly larger than the nuclear PI-stained areas, suggesting that other types of RAR $\alpha$ proteins in the Tumor-NB4 and Tumor-K562 groups were in the cytoplasm and nucleus.

\section{Discussion}

The PML-RAR $\alpha$ gene has an important role in the initiation and progression of APL and is a marker of the disease. The PML-RAR $\alpha$ protein blocks the differentiation of hematopoietic progenitor cells (15). The importance of the PML-RAR $\alpha$ gene has been confirmed in transgenic mice (16). Direct DNA-binding is indispensable for PML/RARA to transform hematopoietic cells and the disruption of PML-nuclear bodies is not sufficient for full cell leukemic transformation (17); however, disruption of PML may facilitate the acquisition of leukemia-promoting mutations by disabling oncogene-induced senescence (18).

However, the entire PML-RAR $\alpha$ fusion protein is not necessary for the development of APL (19,20). Lane and Ley $(11,21)$ found that the PML-RAR $\alpha$ protein can be cleaved by NE in early myeloid cells, resulting in two new mutants: PML, named PML (NLS-), and RAR $\alpha$, named NLS-RAR $\alpha$. RAR $\alpha$ and PML are regulatory proteins implicated in various aspects of differentiation and development (22) and apoptosis and cellular senescence $(23,24)$, respectively. Mutations of RAR $\alpha$ and PML may cause aberrant subcellular localization, insufficient sumoylation, and/or multimerization (25). It has previously been demonstrated that fusion of RAR $\alpha$ with self-associating domains is sufficient to render RAR $\alpha$ leukemogenic (26), and the combination of staurosporine and ATRA may overcome granulocytic differentiation block in retinoid-resistant APL cell lines (27).

Our previous study indicated that PML (NLS-) is a putative tumor promoter factor in human leukemia cells, and downregulation PML (NLS-) expression inhibited the proliferation of HL-60 cells and induced apoptosis (28). Wild-type RAR $\alpha$ inhibits cell growth and promotes differentiation in response to ATRA, whereas NLS-RAR $\alpha$ has the opposite effect (15). Using a yeast two-hybrid system and co-immunoprecipitation techniques, it was demonstrated that NLS-RAR $\alpha$ protein interacted with JTV1 protein, ubiquilin 1 protein and glutamate ammonia ligase (12-14). NLS-RAR $\alpha$ was able to promote cell proliferation and induce cell differentiation, which is inhibited by ATRA though the expression of c-myc (12-14). In response to ATRA, wild-type RAR $\alpha$ inhibits cell growth and promotes differentiation, whereas NLS-RAR $\alpha$ does the opposite. We hypothesize that this difference may be associated with abnormal cellular localization of the RAR $\alpha$ domain, which may result in abnormal protein-protein interactions. This would alter the original signal pathway and biological function, and subsequently promote the occurrence and development of APL.

The NB4 cell line is widely used in the investigation of APL, because it exhibits the typical t $(15 ; 17)(15 q 22 ; 17 q 21)$ translocation and the characteristics of PML-RAR $\alpha$ fusion gene (9-11,21). However, it was discovered that there are no NE enzyme in NB4 cells (10). Therefore, the present study established a NE-NB4 model by electroporation to explore the location of NLS-RAR $\alpha$. The results showed that NLS-RAR $\alpha$ may be detected in the nucleus by western blotting, and the results of immunofluorescence and confocal laser scanning suggested that it was predominantly located in the cell nucleus. This would alter the original signal pathway and biological function, thus promoting the occurrence and development of APL.

In conclusion, the abnormal cellular localization of NLS-RAR $\alpha$ protein, which is likely to result in abnormal protein-protein interactions, may be associated with cell growth and differentiation and this may be one of the occurrence mechanisms of APL.

\section{Acknowledgements}

This study was supported by the National Natural Science Foundation of China (grant no. 81171658) and Natural Science Foundation Project of CQ CSTC (grant no. 2011BA5037).

\section{References}

1. Mattei MG, Petkovich M, Mattei JF, Brand N and Chambon P: Mapping of the human retinoic acid receptor to the q21 band of chromosome 17. Hum Genet 80: 186-188, 1988.

2. Glass CK, DiRenzo J, Kurokawa R and Han ZH: Regulation of gene expression by retinoic acid receptors. DNA Cell Biol 10: 623-638, 1991.

3. Rochette-Egly C and Germain P: Dynamic and combinatorial control of gene expression by nuclear retinoic acid receptors(RARs). Nucl Recept Signal 7: e005, 2009.

4. Gronemeyer H, Gustafsson JA and Laudet V: Principles for modulation of the nuclear receptor superfamily. Nat Rev Drug Discov 3: 950-964, 2004.

5. Saurin AJ, Borden KL, Boddy MN and Freemont PS: Does this have a familiar RING? Trends Biochem Sci 21: 208-214, 1996.

6. Kakizuka A, Miller WH Jr, Umesono K, Warrell RP Jr, Frankel SR, Murty VV, Dmitrovsky E and Evans RM: Chromosomal translocation $\mathrm{t}(15 ; 17)$ in human acute promyelocytic leukemia fuses RAR alpha with a novel putative transcription factor, PML. Cell 66: 663-674, 1991.

7. Soo JY, Seob EJ, Lee JH, Seo YH, Park PW and Ahn JY: A complex, four-way variant $\mathrm{t}(15 ; 17)$ in acute promyelocytic leukemia. Cancer Genet Cytogenet 167: 168-171, 2006.

8. Pollock JL, Westervelt P, Walter MJ, Lane AA and Ley TJ: Mouse models of acute. Curr Opin Hematol 8: 206-211, 2001.

9. Laurenzana A, Pettersson F and Miller WH. Role of PML/RAR $\alpha$ in the pathogenesis APL. Drug Discovery Today: Disease Mechanisms 3: 499-505, 2006.

10. Yang R, Zhong L, Yang XQ, Jiang KL, Li L, Song H and Liu BZ Neutrophil elastase enhances the proliferation and decreases apoptosis of leukemia cells via activation of PI3K/Akt signaling. Mol Med Rep 13: 4175-4182, 2016.

11. Lane AA and Ley TJ: Neutrophil elastase cleaves PML-RARalpha and is important for the development of acute promyelocytic leukemia in mice. Cell 115: 305-318, 2003.

12. Wang C, Liang Z, Dong-Sheng W, Liu BZ, Liao F, Hao P, Liu C, Jin DT and Wang CG. Screening and identification of the proteins interacting with NLS-RAR $\alpha$ protein. Progress in Biochemistry and Biophysics 32: 500-505, 2009.

13. Dan Z, Chong W, Bei-Zhong L, Liang Z, Chun-guang W and Yan W. Screening and identification target proteins interacting with the structural domain of PML-C by yeast two-hybrid system techniques. Yi Xue Fen Zi Sheng Wu Xue Za Zhi 7: 242-246, 2010 (In Chinese). 
14. Hu XX, Zhong L, Zhang X, Gao YM and Liu BZ: NLS-RARo Promotes Proliferation and Inhibits Differentiation in HL-60 Cells. Int J Med Sci 11: 247-254, 2014.

15. Nisole S, Maroui MA, Mascle XH, Aubry $M$ and Chelbi-Alix MK: Differential roles of PML isoforms. Front Oncol 3: 125, 2013.

16. Wartman LD, Welch LJ, Uy GL, Klco JM, Lamprecht T, Varghese N, Nagarajan R and Ley TJ: Expression and function of PML-RARA in the hemotopoietic progenitor cells of Ctsg-PML-RARA mice. PLoS One 7: e46529, 2012.

17. Liu X, Yuan H, Peres L, Chen S, Chen Z, de The H, Zhou J and Zhu J: The DNA binding property of PML/RARA but not the integrity of PML nuclear bodies is indispensable for leukemic transformation. PLoS ONE 9: e104906, 2014.

18. Korfa K, Wodrichb H, Haschkea A, Ocampo C, Harder L, Gieseke F, Pollmann A, Dierck K, Prall S, Staege H, et al: The PML domain of PML-RAR $\alpha$ blocks senescence to promote leukemia. Proc Natl Acad Sci USA 111: 12133-12138, 2014.

19. Hayakawa F and Privalsky ML: Phosphorylation of PML by mitogen-activated protein kinases plays a key role in arsenic trioxide-mediated apoptosis. Cancer Cell 5: 389-401, 2004.

20. Shima Y, Shima T, Chiba T, Irimura T, Pandolfi PP and Kitabayashi I: PML activates transcription by protecting HIPK2 and p300 from SCFFbx3-mediated degradeation. Mol Cell Biol 28: 7126-7138, 2008.
21. Lane AA and Ley TJ: Neutrophil elastase is important for PML-retinoic acid receptor alpha activities in early myeloid cells. Mol Cell Biol 25: 23-33, 2005.

22. Giguere V, Ong ES, Segui P and Evans RM: Identification of a receptor for the morphogen retinoic acid. Nature 330: 624-629, 1987.

23. Wang ZG, Ruggero D, Ronchetti S, Zhong S, Gaboli M, Rivi R and Pandolfi PP: PML is essential for multiple apoptotic pathways. Nat Genet 20: 266-272, 1998

24. Ferbeyre G, de Stanchina E, Baptiste N, Prives C and Lowe SW: PML is induced by oncogenic ras and promotes premature senescence. Genes Dev 14: 2015-2027, 2000.

25. Goto E, Tomita A, Hayakawa F, Atsumi A, Kiyoi H and Naoe T: Missense mutations in PML-RARA are critical for the lack of responsiveness to arsenic trioxide treatment. Blood 118: 1600-1609, 2011.

26. Sternsdorf T, Phan VT, Maunakea ML, Ocampo CB, Sohal J, Silletto A, Galimi F, Le Beau MM, Evans RM and Kogan SC: Forced retinoic acid receptor alpha homodimers prime mice for APL-like leukemia. Cancer Cell 9: 81-94, 2006.

27. Ge DZ, Sheng Y and Cai X: Combined staurosporine and retinoic acid induces differentiation in retinoic acid resistant acute promyelocytic leukemia cell lines. Sci Rep 4: 4821, 2014.

28. Gao YM, Zhong L, Zhang X, Hu XX and Liu BZ: PML (NLS(-)) Inhibits Cell Apoptosis and Promotes Proliferation in HL-60 Cells. Int J Med Sci 10: 498-507, 2013. 